\title{
A new global zenith tropospheric delay model IGGtrop for GNSS applications
}

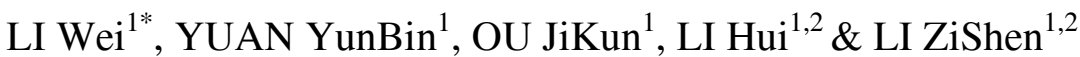 \\ ${ }^{1}$ State Key Laboratory of Geodesy and Earth's Dynamics, Institute of Geodesy and Geophysics, Chinese Academy of Sciences, Wuhan 430077, \\ China; \\ ${ }^{2}$ Graduate University of Chinese Academy of Sciences, Beijing 100049, China
}

Received November 17, 2011; accepted January 18, 2012; published online March 31, 2012

\begin{abstract}
Tropospheric delay is one of the main sources of measurement error in global navigation satellite systems. It is usually compensated by using an empirical correction model. In this paper, temporal and spatial variations of the global zenith tropospheric delay (ZTD) are further analyzed by ZTD time series from global International GNSS Service stations and annual ZTDs derived from global National Centers for Environmental Prediction reanalysis data, respectively. A new ZTD correction model, named IGGtrop, is developed based on the characteristics of ZTD. Experimental results show that this new 3D-grid-based model that accommodates longitudinal as well as latitudinal variations of ZTD performs better than latitude-only based models (such as UNB3, EGNOS, and UNB3m). The global average bias and RMS for IGGtrop are about $-0.8 \mathrm{~cm}$ and $4.0 \mathrm{~cm}$, respectively. Bias values for UNB3, EGNOS, and UNB3m are 2.0, 2.0, and $0.7 \mathrm{~cm}$, respectively, and respective RMS values 5.4, 5.4, and 5.0 cm. IGGtrop shows much more consistent prediction errors for different areas than EGNOS and UNB3m. In China, the performance of IGGtrop (bias values from -2.0 to $0.4 \mathrm{~cm}$ and RMS from 2.1 to $6.4 \mathrm{~cm}$ ) is clearly superior to those of EGNOS and UNB3m. It is also demonstrated that IGGtrop biases vary little with height, and its RMS values tend to decrease with increasing height. In addition, IGGtrop generally estimates ZTD with greater accuracy than EGNOS and UNB3m in the Southern Hemisphere.
\end{abstract}

zenith tropospheric delay (ZTD), global zenith tropospheric delay model, EGNOS, UNB3, UNB3m, IGGtrop

Citation: $\quad$ Li W, Yuan Y B, Ou J K, et al. A new global zenith tropospheric delay model IGGtrop for GNSS applications. Chin Sci Bull, 2012, 57: 2132-2139, doi: 10.1007/s11434-012-5010-9

Tropospheric delay is one of the major error sources in satellite navigation. Global Navigation Satellite System (GNSS) signal transmission delay caused by the troposphere can vary from about $2.5 \mathrm{~m}$ at the zenith to over $20 \mathrm{~m}$ at lower elevation angles between receiver and satellite (e.g. below $15^{\circ}$ ). In most GNSS applications, this tropospheric delay effect is normally mitigated by empirical prediction models.

Conventional models, such as Hopfield or Saastamoinen, which can estimate the tropospheric delay at centimeter to decimeter level using direct meteorological measurements, are not suitable for real-time precise positioning and navigation. Using reference atmospheric information will obvi-

*Corresponding author (email: liweifreedom@ hotmail.com) ously reduce the accuracy of those models. So Collins and Langley [1] developed the UNB3 model for Wide Area Augmentation System users. In the UNB3 algorithm, a look-up table of five atmospheric parameters (pressure, temperature, water vapor pressure, temperature lapse rate, and water vapor pressure height factor) that vary with latitude and day of year is used to calculate the surface meteorology. The zenith delay errors of UNB3 are basically within $\pm 20 \mathrm{~cm}$ for the North American area, and the average is about $2 \mathrm{~cm}$ [2]. The accuracy of UNB3 is comparable to that of either Hopfield or Saastamoinen models when they are used with real-time atmospheric parameters. But UNB3 shows greater accuracy than the Hopfield model for stations above $1 \mathrm{~km}$ elevation [3]. A modified version of UNB3, called EGNOS, is a model recommended by the Interna- 
tional Civil Aviation Organization (ICAO) [4]. It is now widely used in the Satellite-Based Augmentation Systems of the USA [1,2], Europe [5,6], and Japan [7]. To accomplish a more accurate correction of tropospheric delay, many new versions of the UNB model have been developed during the last few years. For example, the UNB3m is created by replacing the water vapor pressure in the UNB3 look-up table by relative humidity. This modification improves the accuracy of wet delay modeling and average model bias is reduced to about $-0.5 \mathrm{~cm}[8,9]$. UNBw.na is a regional model for North America, which adopts a twodimensional grid table instead of the UNB3 latitude-band look-up table [10]. UNBw.na has proven to be a more reliable model and has more homogeneous results for varying locations than either UNB3 or UNB3m. However, grid generation is complex.

Models, such as UNB3, UNB3m and EGNOS, which are based on the latitude-band look-up table of meteorological parameters, cannot reflect zonal variation of the zenith tropospheric delay (ZTD). So model errors in some regions can be much greater than the global average value. UNBw.na overcomes this problem, but its efficiency is only suitable in North America. For Chinese researchers, several localized tropospheric delay models have been built for certain areas in China [11-13]. However, there are only a few preliminary studies on building such models for all of China [14] or for a global scale [15].

In this study, we begin by further investigating comprehensive temporal and spatial variations of global ZTD by GNSS-derived ZTD and National Centers for Environmental Prediction (NCEP) reanalysis data, respectively. Then, a new empirical ZTD model called IGGtrop is developed based on a three-dimensional grid (lat. $\times$ long. $\times$ height) through an easily-implemented procedure. Experimental results show that IGGtrop can estimate the zenith delay at the centimeter level without real-time meteorological measurements. Furthermore, this grid-based model has more consistent and relatively less error for different regions, compared to EGNOS and UNB3m. So IGGtrop may serve as a reference tropospheric delay correction model for the satellite navigation and positioning system built by China, i.e. its GNSS.

\section{ZTD characteristics analysis}

Since comprehensive knowledge about the characteristics of ZTD is fundamental to its modeling, in this section the temporal variation of ZTD is analyzed by a set of continuous GNSS measurements, and ZTD obtained from the NCEP reanalysis data is used to investigate its spatial distribution.

Since most tropospheric delay models are based on meteorology data from traditional instruments, the GNSSderived ZTD with high accuracy and spatial-temporal reso- lution has become a new data source for atmospheric research and ZTD modeling. Since 1998, the International GNSS Service (IGS) has regularly provided a ZTD product at 2-h time intervals for services based on IGS tracking stations [16]. The mean uncertainty of the IGS ZTD product is about $4 \mathrm{~mm}$. Here, we choose ZTD estimates from 125 global IGS sites from 2001-2005 to study ZTD temporal variation. Figure 1 plots a 5-year continuous ZTD time series observed at six IGS sites (wuhn, bjfs, lhas, kour, nyal, and drao). The ZTD time series are analyzed with the Fast Fourier transform and the corresponding PSD (power spectral density) results are included in the figure. This clearly reveals peaks for the annual and semiannual periods. The annual component overwhelms the semiannual one at 5 sites, except at kour which is near the equator. No obvious inter-annual variation is evident in the 5-year ZTD observations of the figure. To determine the annual and semiannual components in ZTDs, equation (1) is used to fit the ZTD time series from all 125 sites:

$$
\begin{aligned}
\mathrm{ZTD}= & \text { Mean }- \text { Ampl } \cdot \cos \left(\frac{2 \pi}{365.25}(\mathrm{DOY}-D 1)\right) \\
& - \text { Amp } 2 \cdot \cos \left(\frac{4 \pi}{365.25}(\mathrm{DOY}-\mathrm{D} 2)\right), \\
\mathrm{ZTD}= & \text { Mean }- \text { Ampl } \cdot \cos \left(\frac{2 \pi}{365.25}(\mathrm{DOY}-D 1)\right),
\end{aligned}
$$

where DOY refers to the day of year, and ZTD to the zenith tropospheric delay. The unknown parameters (Mean, Amp1, D1, Amp2, and D2) in eq. (1) are estimated using the method of least squares; Mean refers to the ZTD annual mean, Amp1(2) and D1(2) are the amplitude and phase for the annual (semiannual) component, respectively. Statistical results show the following characteristics. In the equatorial band $\left(15^{\circ} \mathrm{S}-15^{\circ} \mathrm{N}\right)$, Amp2 is greater than Amp1 at four sites, and the mean of Amp2/Amp1 is about 1.4. For the other 7 sites in this region, Amp1 is larger than Amp2. Outside the equatorial band, Amp1 is greater than Amp2 at all sites. According to the foregoing analysis, the ZTD time series for sites outside the equatorial region are fitted again with a simpler equation (2), which has no semiannual component. The annual phase D1 in eq. (2) indicates the time of seasonal minimum. For sites outside the equatorial band, the D1s (eq. (2)) are in January or February for the Northern Hemisphere (NH), and in July or August for the Southern Hemisphere $(\mathrm{SH})$. This reveals that the ZTD value peaks in summer and minimizes in winter. For all six sites in Figure 1 , it is seen that cosine curve fitting results (the thick solid line overlapping the ZTD time series) represent ZTD temporal variation very well. The RMS of the ZTD fit residual is between 1.7 and $6.4 \mathrm{~cm}$ for all sites, and the average RMS is $3.6 \mathrm{~cm}$. Based on multi-year ZTD observations from 150 IGS sites, Jin [17] reported temporal characteristics of ZTD similar to our study, except for the equatorial 

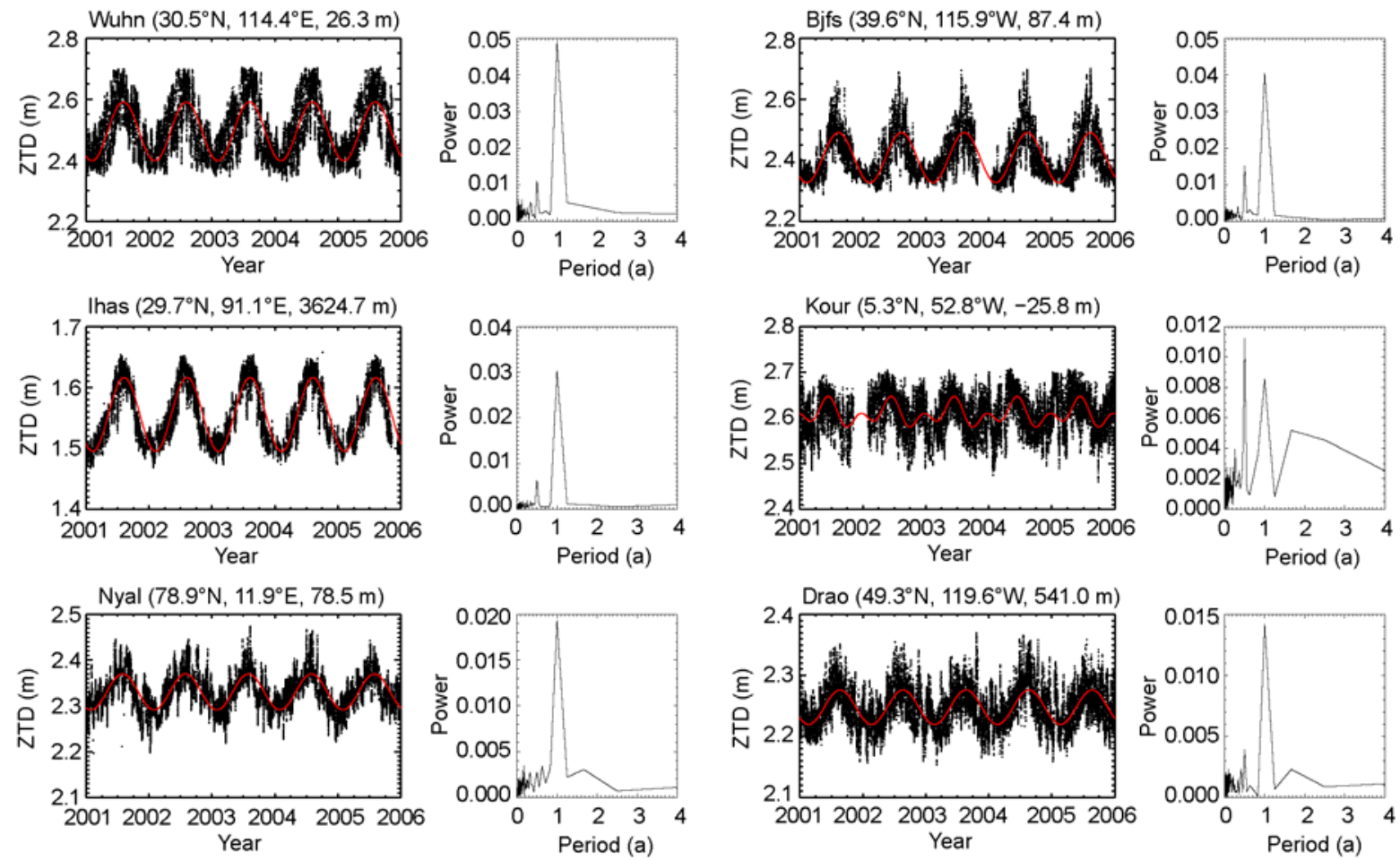

Figure 1 ZTD time series at six IGS sites (wuhn, bjfs, lhas, kour, nyal, and drao) and the corresponding PSD results. Thick solid line overlapping the ZTD time series is the result of cosine curve fit.

belt. Our results indicate that unlike at mid and high latitudes, the semiannual component may be important in the temporal variation of equatorial ZTD, which has not been previously reported by other researchers.

Because of the uneven coverage and different elevations of IGS sites, we use the NCEP reanalysis data to illustrate the horizontal distribution of global ZTD. The NCEP provides gridded reanalysis data with a horizontal resolution of $2.5^{\circ} \times 2.5^{\circ}$ at 17 pressure levels [18]. Pressure, temperature and relative humidity data from NCEP in 2004 are used to calculate atmospheric refractivity. Then the ZTD is obtained by integrating refractivity along a vertical path through the neutral atmosphere [19]:

$$
\begin{gathered}
N=\frac{k_{1}(P-e)}{T}+\frac{k_{2} e}{T}+\frac{k_{3} e}{T^{2}}, \\
\mathrm{ZTD}=10^{-6} \int_{h_{0}} N \mathrm{~d} h,
\end{gathered}
$$

where $k_{i}(i=1,2,3)$ is a set of known constant parameters, $P$ is the atmospheric pressure, $T$ is the temperature, $e$ is the water vapor pressure, $N$ is the atmospheric refractivity, and $h$ is the height. $e$ is calculated by the following formula [20]:

$$
e=0.01 \mathrm{RH} \cdot e_{\mathrm{s}} \cdot f_{\mathrm{w}},
$$

where $\mathrm{RH}$ is the relative humidity, $e_{\mathrm{s}}$ is the saturation water vapor pressure, and $f_{\mathrm{w}}$ is the enhancement factor. Since the top level of NCEP data only reaches $10 \mathrm{hPa}$, ZTD above this level is calculated by the atmospheric parameters (without water vapor) derived from the Mass-SpectrometerIncoherent-Scatter (MSIS00) model (about $0.023 \mathrm{~m}$ ).

Figure 2 shows the global distribution of annual mean ZTD at mean sea level, derived from the NCEP data in 2004 via the method described above. Although the global ZTD distribution is mainly associated with latitude (it tends to decrease with latitude), there is also clear zonal variation in some latitude belts. Statistical results show that zonal ZTD variation ranges from 1.5 to $26 \mathrm{~cm}$ with a mean of $9 \mathrm{~cm}$. Such zonal variation is much more predominant in the $\mathrm{NH}$ than in the SH. In the NH, ZTD spatial distribution is complicated, especially near coastlines, which may be attributed to the uneven distribution of continents and oceans on the earth's surface. For the SH, which is mostly covered by

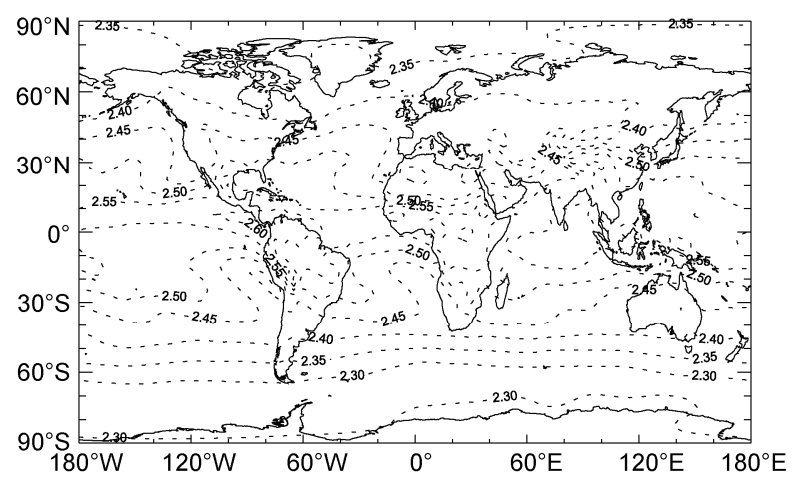

Figure 2 Global distribution of annual mean ZTD at mean sea level (m). 
ocean, ZTD contours appear to parallel latitude circles. Most tropospheric delay models $[1,5,6,8]$ consider the ZTD to be symmetric between $\mathrm{NH}$ and $\mathrm{SH}$. However, this assumption seems too coarse relative to the ZTD spatial characteristics discussed above. This may cause large biases in certain local areas for those models. In the China region, ZTD distribution has more zonal structure than around North America. The horizontal gradient of ZTD is greater in western China than in its east. Hence, to achieve more realistic prediction and correction performance, zonal ZTD variation must also be taken into account as much as possible in ZTD modeling.

\section{A new global ZTD model-IGGtrop}

The ZTD analysis in the above section shows that temporal ZTD variation is dominated by the annual and semiannual components, which can be resolved by the fit of a 1-year cosine curve or the joint fit of a 1.0- and a 0.5-year cosine curves. The global ZTD spatial distribution shows complex pattern because of its zonal variation. In view of this complicated spatial structure, a new global ZTD model called IGGtrop is proposed, based on a three-dimensional grid as follows.

(1) Define the latitude-longitude-height grid $\left(\varphi_{i}, \lambda_{j}, h_{k}\right)(\varphi$ : latitude, $\lambda$ : longitude, $h$ : height) of the model with uniform horizontal and height resolution $(\Delta \varphi, \Delta \lambda, \Delta h) . \Delta h$ determination depends on the height resolution of the meteorology data used for creating the ZTD model. For meteorology data with uniform horizontal resolution $\left(\Delta \varphi_{a}, \Delta \lambda_{a}\right)$, set $\Delta \varphi \geqslant \Delta \varphi_{a}$, $\Delta \lambda \geqslant \Delta \lambda_{a}$. This means that the horizontal resolution of the model grid may be somewhat coarser than that of the meteorology data when the desired prediction accuracy is relatively low. For meteorology data with uneven horizontal resolution, $\Delta \varphi$ and $\Delta \lambda$ are determined by the spatial density of data and the desired prediction accuracy.

(2) Calculate $\operatorname{ZTD}(\varphi, \lambda, h, t)$ from atmospheric pressure $(P(\varphi, \lambda, h, t))$, temperature $(T(\varphi, \lambda, h, t))$, relative humidity $(\mathrm{RH}(\varphi, \lambda, h, t))$ or water vapor pressure $(e(\varphi, \lambda, h, t))$, using the method in section 1 ( $t$ refers to time (unit: d)). Then, interpolate $\operatorname{ZTD}(\varphi, \lambda, h, t)$ to all the grids to obtain the ZTD time series $\operatorname{ZTD}\left(\varphi_{i}, \lambda_{j}, h_{k}, t\right)$. Spatial interpolation is done in two steps. First, because ZTD decreases approximately exponentially with increasing height [17], interpolate the natural logarithm of $\operatorname{ZTD}(\varphi, \lambda, h)$ to the height grid with spline interpolation, then obtain $\operatorname{ZTD}\left(\varphi, \lambda, h_{k}\right)$. Second, interpolate $\operatorname{ZTD}\left(\varphi, \lambda, h_{k}\right)$ to the horizontal grid to attain $\operatorname{ZTD}\left(\varphi_{i}, \lambda_{j}, h_{k}\right)$ by bilinear interpolation. However, when $\Delta \varphi=\Delta \varphi_{a}, \Delta \lambda=\Delta \lambda_{a}$ is met, the horizontal interpolation step is omitted.

(3) Fit the ZTD time series $\operatorname{ZTD}\left(\varphi_{i}, \lambda_{j}, h_{k}, t\right)$ with eq. (6) and calculate the IGGtrop model parameters on all grids. For areas outside the equatorial band, model parameters are annual mean ZTD $\left(\operatorname{meanZTD}\left(\varphi_{i}, \lambda_{j}, h_{k}\right)\right)$ and amplitude $\left(\operatorname{ampZTD}\left(\varphi_{i}, \lambda_{j}, h_{k}\right)\right)$ of the annual cycle. Phase $D$ is a fixed value, 28 for the $\mathrm{NH}$ and 210 for the SH. For areas inside the equatorial band, model parameters are annual mean ZTD $\left(\operatorname{meanZTD}\left(\varphi_{i}, \lambda_{j}, h_{k}\right)\right)$, amplitude $\left(\operatorname{ampZTD} 1\left(\varphi_{i}, \lambda_{j}, h_{k}\right)\right)$ and phase (D1 $\left.\left(\varphi_{i}, \lambda_{j}, h_{k}\right)\right)$ of the annual cycle, and amplitude $\left(\operatorname{ampZTD} 2\left(\varphi_{i}, \lambda_{j}, h_{k}\right)\right)$ and phase $\left(\mathrm{D} 2\left(\varphi_{i}, \lambda_{j}, h_{k}\right)\right)$ of the semiannual cycle.

$$
\operatorname{ZTD}\left(\varphi_{i}, \lambda_{j}, h_{k}, t\right)=\left\{\begin{array}{l}
\operatorname{meanZTD}\left(\varphi_{i}, \lambda_{j}, h_{k}\right) \\
\quad-\operatorname{ampZTD}\left(\varphi_{i}, \lambda_{j}, h_{k}\right) \\
\quad \times \cos \left(\frac{2 \pi}{365.25}(t-D)\right), \\
15^{\circ} \mathrm{S}<\varphi_{i} \leqslant 90^{\circ} \mathrm{S} \text { or } 15^{\circ} \mathrm{N}<\varphi_{i} \leqslant 90^{\circ} \mathrm{N}, \\
\operatorname{meanZTD}\left(\varphi_{i}, \lambda_{j}, h_{k}\right) \\
\quad-\operatorname{ampZTD} 1\left(\varphi_{i}, \lambda_{j}, h_{k}\right) \\
\quad \times \cos \left(\frac{2 \pi}{365.25}\left(t-D 1\left(\varphi_{i}, \lambda_{j}, h_{k}\right)\right)\right), \\
\quad-\operatorname{ampZTD} 2\left(\varphi_{i}, \lambda_{j}, h_{k}\right) \\
\quad \times \cos \left(\frac{4 \pi}{365.25}\left(t-D 2\left(\varphi_{i}, \lambda_{j}, h_{k}\right)\right)\right), \\
15^{\circ} \mathrm{S} \leqslant \varphi_{i} \leqslant 15^{\circ} \mathrm{N} .
\end{array}\right.
$$

(4) Calculate ZTD at site $\mathrm{A}(\varphi, \lambda, h)$. First, identify the grid $(i, j, k)$ on which A lies. Then, compute ZTDs on the grids $\left(\varphi_{i}, \lambda_{j}, h_{k=1: N}\right)$ ( $N$ is the total number of height grids) with corresponding model parameters of the grids and the observation time (day of year), using eq. (6). Finally, interpolate ZTD $\left(\varphi_{i}, \lambda_{j}, h_{k=1: N}\right)$ to the height of site A by the same method used in step (2).

The IGGtrop model is generated based on four years of NCEP data between 2006 and 2009 with temporal resolution of one day. The model grid is $2.5^{\circ} \times 2.5^{\circ} \times 1 \mathrm{~km}$, which is the same horizontal resolution as the NCEP data. The highest level of IGGtrop is $25 \mathrm{~km}$. Although the algorithm of parameters on the three-dimensional grid is relatively simple for IGGtrop, the model provides high-accuracy estimation of ZTD without real-time atmospheric measurements.

\section{IGGtrop model validation}

To assess the accuracy and performance of the IGGtrop model, its ZTD predictions are compared to the actual ZTD measurements. In this approach, GNSS-derived ZTD values from 125 global IGS sites during 2001-2005 are used as a reference ('true ZTD'). For each site, we compute average bias (model minus observation) and RMS difference between the ZTDs derived from model and observation. General statistics of zenith delay prediction performance of IGGtrop, UNB3, EGNOS, and UNB3m are shown in Table 1.

As seen in Table 1, ZTD can be predicted at the centimeter level by the IGGtrop model. It has a global mean bias 
Table 1 Statistics of global mean bias and RMS for IGGtrop, UNB3, EGNOS, and UNB3m models ${ }^{\text {a) }}$

\begin{tabular}{cccc}
\hline & IGGtrop & EGNOS & UNB3 \\
\hline Bias $(\mathrm{cm})$ & $-0.8(-5.8,2.7)$ & $2.0(-5.4,12.6)$ & $2.0(-5.4,12.6)$ \\
RMS $(\mathrm{cm})$ & $4.0(2.1,7.9)$ & $5.4(2.1,14.0)$ & $5.4(2.0,14.0)$ \\
\hline
\end{tabular}

a) Values in brackets show the minima and maxima of both bias and RMS for all 125 IGS sites, 2001-2005.

around $-0.8 \mathrm{~cm}$ and RMS close to $4.0 \mathrm{~cm}$. Although the absolute bias of IGGtrop is similar to that of UNB3m, it is much lower than that of UNB3 and EGNOS. Besides the improvement in bias, IGGtrop has smaller RMS values than the other three models. Compared to UNB3, the mean bias is reduced by about $70 \%$ for UNB3m, but RMS improvement is small. Because of the very similar prediction errors between UNB3 and EGNOS, we only discuss the statistics of EGNOS in the following analysis. The mean bias of $\mathrm{UNB} 3 \mathrm{~m}$ is positive, opposite the results of Leandro et al. [8]. This may be caused by the different geographic locations where ZTD observations were selected for model validation. They calculated model error across North America, whereas our analysis considers the global mean error.

Figure 3 shows the histograms of bias and RMS values for IGGtrop, EGNOS and UNB3m. The IGGtrop bias is between -6 and $6 \mathrm{~cm}$, and RMS between 2 and $8 \mathrm{~cm}$. From Figure 3, we see that histograms of both IGGtrop bias and RMS are much more centralized than those of the other two models, which indicates that IGGtrop performs more homogeneously in localized areas. On the other hand, calculations also show that if zonal ZTD variation is not considered in IGGtrop, the range of its bias extends to $\pm 9 \mathrm{~cm}$ and the mean RMS increases to about $4.6 \mathrm{~cm}$. The above analyses indicate that a 3D-grid-based model that accommodates longitudinal and latitudinal ZTD variation is generally more realistic than a latitude-only-based model for various regions.

The mean bias values of IGGtrop at all 125 IGS sites are shown in Figure 4, where it can be seen that absolute bias values are smaller at inland sites than acean or coastal locations. In addition, IGGtrop biases are mostly positive at inland continental locations and negative over oceans and coasts. It is noticed that all the three sites with absolute bias greater than $3 \mathrm{~cm}$ are in equatorial regions. Since radiosonde observation is the main data source for NCEP reanalysis, we check radiosonde data near the three equatorial sites with large biases, finding that these data are generally incomplete and of poor quality. This indicates that large biases may result from inaccurate equatorial NCEP data used for computing model parameters. Therefore adding other high-quality meteorology data to the IGGtrop model may improve its accuracy near the equator.

The six plots in Figure 5 show the distributions of model bias and RMS with respect to height, latitude and longitude for IGGtrop and UNB3m. To show more detailed results, the IGS sites are divided into intervals of latitude or height. Tables 2 and 3 present the results of IGGtrop, EGNOS and UNB3m for each height and latitude interval, respectively. In Table 2, one can see that IGGtrop performs better than EGNOS and UNB3m for heights below $0.5 \mathrm{~km}$ or above 2 $\mathrm{km}$. For heights between 0.5 and $2 \mathrm{~km}$, the performance of IGGtrop is similar to or a little better than either EGNOS or UNB3m. The bias of IGGtrop is relatively constant with
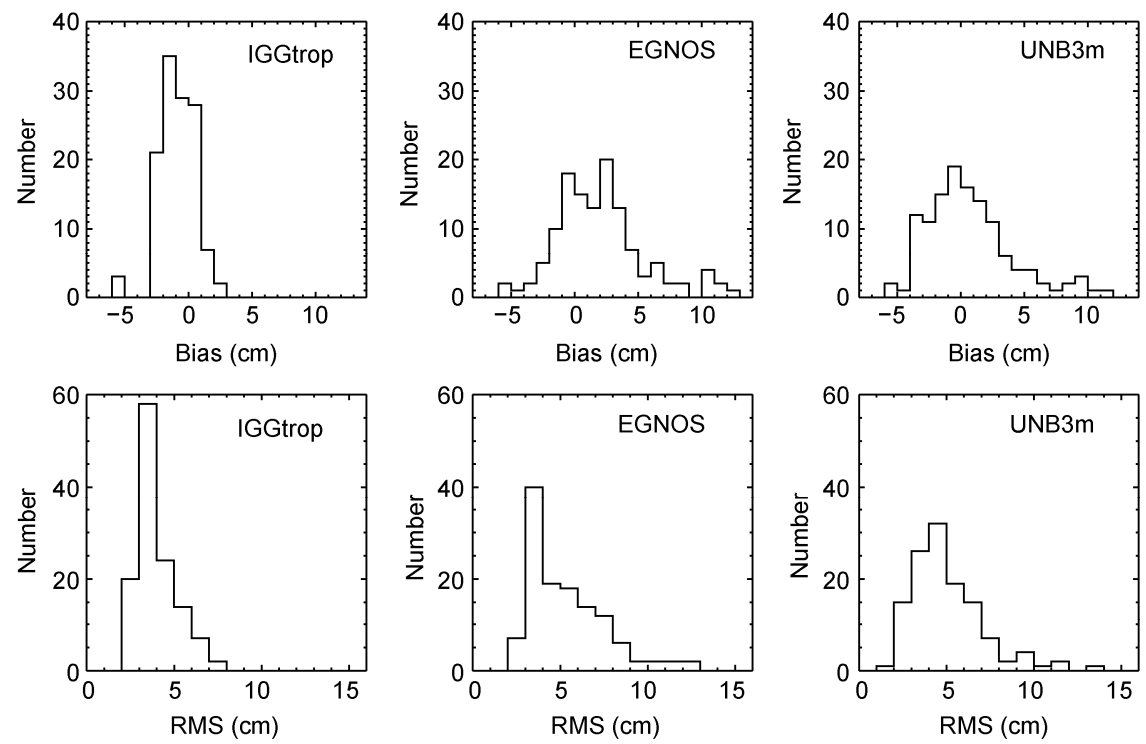

Figure 3 Histograms of bias and RMS for IGGtrop, EGNOS and UNB3m. 


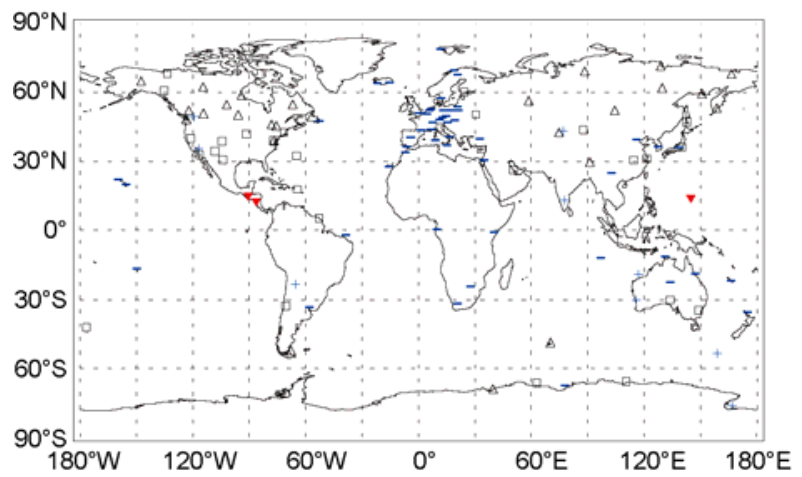

Figure 4 Mean bias values for all 125 IGS sites. Symbols designate locations of IGS sites. Various symbols represent different bias ranges. $\triangle$, $[0,1] \mathrm{cm} ; \square,[-1,0) \mathrm{cm} ;+,(1,3] \mathrm{cm} ;-,[-3,-1) \mathrm{cm} ; \mathbf{\nabla},[-6,-3) \mathrm{cm}$.

heights, whereas its RMS value decreases with same. For UNB3m, bias clearly decreases with height, which is similar to the feature of UNB3m error reported by Leandro et al. [8]. Because of the complicated relationship between ZTD and height, many tropospheric delay models use simplified formulae for ZTD. However, such simplification may result in systematic error with height. By using a height grid instead of biased ZTD formulae, IGGtrop performs consistently at different heights.

From Table 3 and Figure 5, it is seen that the bias of IGGrop is approximately proportional to latitude. Mean bias values in all latitude bands shown in Table 3 are negative. The absolute mean bias of IGGtrop near the equator is approximately twice that in other latitude bands. This is attributed to the three equatorial IGS sites with large biases mentioned previously. If these three sites are eliminated from the statistics, the mean bias and RMS values in the equator band decrease to -1.1 and $4.9 \mathrm{~cm}$, respectively.
IGGtrop generally performs better than EGNOS and UNB3 $m$ in mid latitudes and polar regions, especially in the $\mathrm{SH}$ or around $30^{\circ} \mathrm{N}$ latitude. In Figure 5, the bias and RMS of IGGtrop show no systematic differences between NH and SH. However, both EGNOS (not shown in the figure) and UNB3m have much lower accuracy in the SH relative to the NH. Thus it is again shown that the assumption of ZTD symmetry between $\mathrm{NH}$ and $\mathrm{SH}$ produces great bias in ZTD models. For longitudinal variation, IGGtrop biases show a wave-like distribution in Figure 5, with two crests near $80^{\circ} \mathrm{E}$ and $110^{\circ} \mathrm{W}$. The previous analysis has shown that IGGtrop bias is positive over inland continental areas, and negative over oceans. Hence the distribution of $\mathrm{NH}$ continents and oceans (most IGS sites are in the NH) generate this wavelike model bias variation with longitude.

Because seasonal variation of atmospheric parameters is small in the equator area, some tropospheric delay models, including EGNOS and UNB3m, treat ZTD between $15^{\circ} \mathrm{S}-15^{\circ} \mathrm{N}$ as constant all the time [1,5-8]. We also find that ZTD annual variation in polar regions is small, compared to that in mid latitudes. Table 3 presents IGGtrop results when seasonal variations are not implemented for latitudes below $15^{\circ}$ and above $75^{\circ}$. It is evident that although the model accuracies for the two latitude bands clearly decrease, they are still comparable to the results for other latitude bands. Hence, when accuracy requirements are relatively low, one can simplify the IGGtrop model by neglecting the seasonal ZTD variation in both equatorial and polar regions.

Table 4 shows mean bias and RMS of IGGtrop, EGNOS, and UNB3m at six IGS sites in China. For all the sites in the table, IGGtrop predicts ZTD more realistically than EGNOS or UNB3m.

Table 2 Statistics of bias and RMS for IGGtrop, EGNOS, and UNB3m in different height bands

\begin{tabular}{|c|c|c|c|c|c|c|c|}
\hline \multirow{2}{*}{ Height (m) } & \multirow{2}{*}{ No. of sites } & \multicolumn{2}{|c|}{ IGGtrop } & \multicolumn{2}{|c|}{ EGNOS } & \multicolumn{2}{|c|}{ UNB3m } \\
\hline & & $\operatorname{Bias}(\mathrm{cm})$ & RMS (cm) & Bias $(\mathrm{cm})$ & RMS (cm) & Bias $(\mathrm{cm})$ & RMS (cm) \\
\hline$<500$ & 86 & -0.8 & 4.2 & 2.6 & 5.9 & 1.1 & 5.4 \\
\hline $1000-2000$ & 16 & -0.8 & 3.5 & 0.4 & 3.8 & -0.4 & 3.7 \\
\hline$>2000$ & 5 & -0.6 & 2.7 & -0.6 & 3.9 & -0.9 & 3.7 \\
\hline
\end{tabular}

Table 3 Statistics of bias and RMS for IGGtrop, EGNOS, and UNB3m in different latitude bands

\begin{tabular}{|c|c|c|c|c|c|c|c|c|c|}
\hline \multirow{2}{*}{ Latitude $\left(^{\circ}\right)$} & \multirow{2}{*}{ No. of sites } & \multicolumn{2}{|c|}{ IGGtrop } & \multicolumn{2}{|c|}{ EGNOS } & \multicolumn{2}{|c|}{ UNB3m } & \multicolumn{2}{|c|}{ IGGtrop (no seasonal variation) } \\
\hline & & $\operatorname{Bias}(\mathrm{cm})$ & RMS (cm) & $\operatorname{Bias}(\mathrm{cm})$ & RMS (cm) & $\operatorname{Bias}(\mathrm{cm})$ & RMS (cm) & Bias $(\mathrm{cm})$ & RMS (cm) \\
\hline $0-15$ & 11 & -2.4 & 5.6 & -1.0 & 6.4 & -1.2 & 6.4 & -2.4 & 6.2 \\
\hline $30-45$ & 43 & -0.8 & 4.1 & 2.7 & 5.4 & 1.5 & 5.0 & - & - \\
\hline $45-60$ & 35 & -0.5 & 3.6 & 1.0 & 4.4 & -0.7 & 4.3 & - & - \\
\hline $60-75$ & 18 & -0.6 & 3.3 & 2.9 & 5.3 & 1.1 & 4.6 & - & - \\
\hline $75-90$ & 3 & -0.4 & 3.2 & 4.7 & 6.2 & 3.3 & 5.5 & -0.4 & 3.9 \\
\hline
\end{tabular}



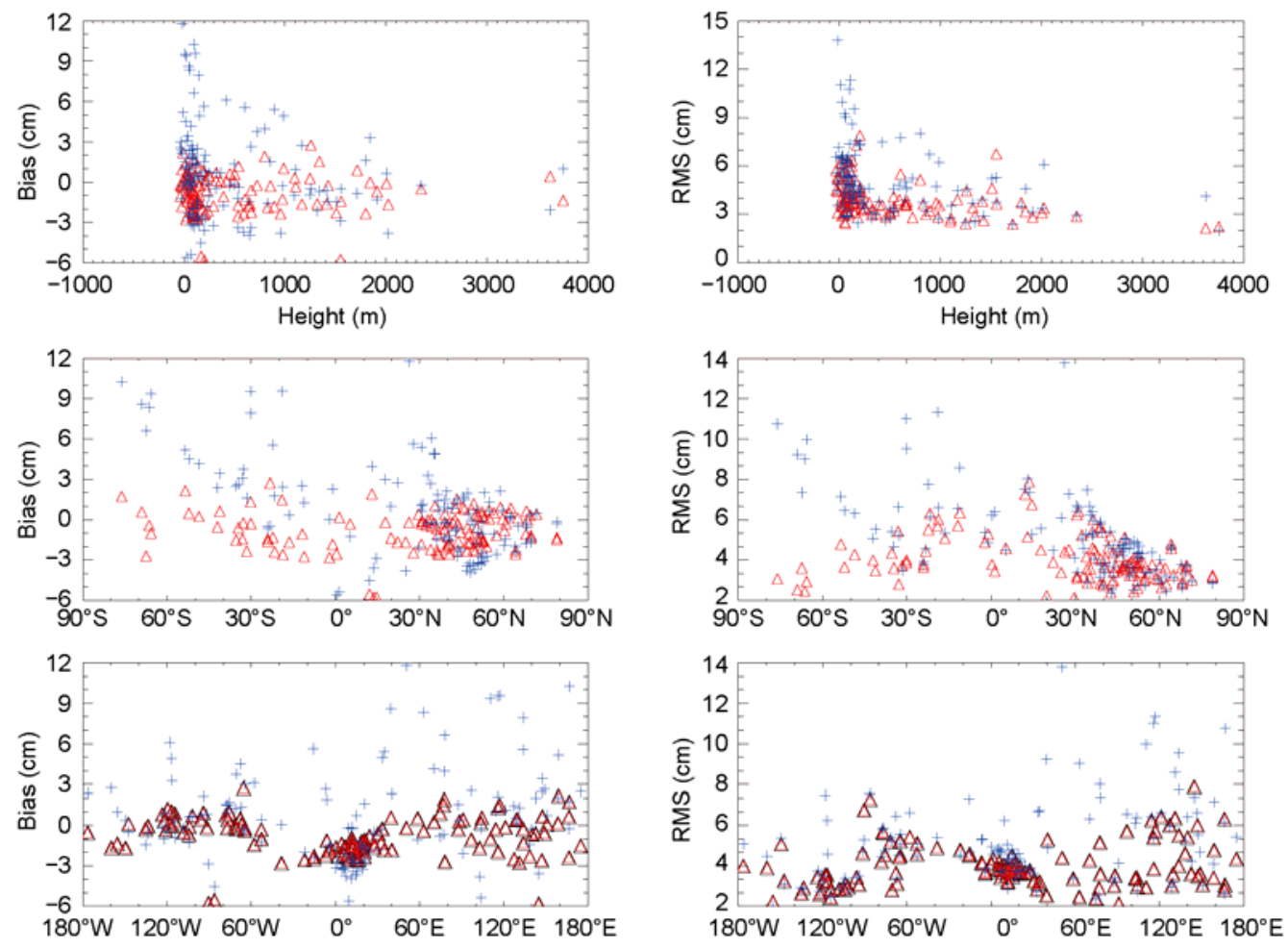

Figure 5 Distributions of bias and RMS with respect to height, latitude, and longitude for IGGtrop $(\Delta)$ and UNB3m (+).

Table 4 Bias and RMS for IGGtrop, EGNOS, and UNB3m at six IGS sites in China $(\mathrm{cm})$

\begin{tabular}{|c|c|c|c|c|c|c|}
\hline \multirow{2}{*}{ Site } & \multicolumn{2}{|c|}{ IGGtrop } & \multicolumn{2}{|c|}{ EGNOS } & \multicolumn{2}{|c|}{ UNB3m } \\
\hline & Bias & RMS & Bias & RMS & Bias & RMS \\
\hline Wuhn (Wuhan) & -0.3 & 6.2 & 1.8 & 7.2 & 1.0 & 6.4 \\
\hline Bjfs (Beijing) & -2.0 & 5.4 & 3.9 & 6.7 & 2.1 & 5.4 \\
\hline Shao (Shanghai) & -0.1 & 6.4 & 2.2 & 7.5 & 1.1 & 6.6 \\
\hline Kunm (Kunming) & -1.7 & 3.4 & -3.5 & 6.2 & -3.8 & 6.1 \\
\hline Urum (Urumqi) & -0.3 & 3.0 & 2.6 & 4.0 & 1.5 & 3.2 \\
\hline Lhas (Lhasa) & 0.4 & 2.1 & -2.0 & 4.3 & -2.1 & 4.1 \\
\hline
\end{tabular}

\section{Conclusions}

In this paper, temporal and spatial characteristics of global ZTD were further studied by ZTD observations derived from GNSS signals and NCEP reanalysis data. A new global ZTD model (called IGGtrop) was established based on a multi-year NCEP reanalysis data set. IGGtrop was validated by comparing zenith delays predicted from model with those derived from 125 global IGS sites. Furthermore, the advantages of IGGtrop were demonstrated by comparing the performance of IGGtrop with the EGNOS and UNB3m models, which were created for Satellite-Based Augmentation Systems. Statistical results show that:

Based on a three-dimensional grid (lat. $\times$ long. $\times$ height), IGGtrop is capable of modeling the zonal as well as meridional variation of ZTD. The procedure used in the genera- tion of the model grid is relatively simple.

Statistical results of the IGGtrop bias and RMS. The global mean bias and RMS of IGGtrop are about $-0.8 \mathrm{~cm}$ and $4.0 \mathrm{~cm}$, respectively. The mean bias of IGGtrop is similar to that of UNB3m, but it is much lower than that of EGNOS. The global mean RMS of IGGtrop is lower than that of EGNOS and UNB3m. IGGtrop has much more consistent modeling performance than EGNOS and UNB3m for different locations. For the six IGS sites in China, IGGtrop biases range from -2.0 to $0.4 \mathrm{~cm}$ and RMS from 2.1 to 6.4 $\mathrm{cm}$, which shows much better results than EGNOS and UNB3m. IGGtrop also has much higher accuracy than EGNOS and UNB3m in the SH.

Distribution of bias and RMS values of IGGtrop. Model biases are relatively constant at various heights, whereas RMS values decrease with height. IGGtrop bias is approximately proportional to latitude. The accuracy of IGGtrop is lowest near the equator, which is the result of the poor-quality equatorial NCEP data used for model creation.

This work is intended to promote the research and application of the ZTD model for the satellite navigation and positioning system of China. For its good correction performance, IGGtrop is expected to be used as a reference ZTD model in the Chinese GNSS.

This work was supported by the National Natural Science Foundation of China (41104103, 41021003, 40890160 and 41074013), the National Science Fund for Distinguished Young Scholars (40625013), and the CAS/ SAFEA International Partnership Program for Creative Research Teams. 
We thank the IGS for providing ZTD data and NOAA for providing NCEP reanalysis data. We thank the two anonymous reviewers for their helpful comments on this paper.

1 Collins J P, Langley R B. A tropospheric delay model for the user of the Wide Area Augmentation System. Final contract report for Nav Canada, Department of Geodesy and Geomatics Engineering Technical Report No. 187, University of New Brunswick, Fredericton, N.B., Canada, 1997

2 Collins J P, Langley R B. The Residual Tropospheric Propagation Delay: How Bad Can It Get? In: ION GPS 1998, September 15-18, Nashville, Tennessee, USA, 1998. 729-738

3 Qu W J, Zhu W Y, Song S, et al. The Evaluation of Precision about Hopfield, Saastamoinen and EGNOS Tropospheric Delay Correction Model (in Chinese). Acta Astronom Sin, 2008, 49: 113-122

4 RTCA/DO-229C. Minimum Operational Performance Standards for Global Positioning System/Wide Area Augmentation System Airborne Equipment. SC-169, RTCA, Inc., Washington D.C., 2001

5 Dodson A H, Chen W, Baker H C, et al. Assessment of EGNOS tropospheric correction model. In: ION GPS 1999, September 14-17, Nashville, Tennessee, USA, 1999. 1401-1407

6 Penna, N, Dodson A, Chen W. Assessment of EGNOS tropospheric correction model. J Navig, 2001, 54: 37-55

7 Uemo M, Hoshinoo K, Matsunaga K, et al. Assessment of atmospheric delay correction models for the Japanese MSAS. In: ION GPS2001, September 11-14, Salt Lake City, Utah, USA, 2001. 2341-2350

8 Leandro R F, Santos M C, Langley R B. UNB neutral atmosphere models: development and performance. In: ION NTM 2006, January 18-20, Monterey, California, USA, 2006. 564-573

9 Leandro R F, Langley R B, Santos M C. UNB3m_pack: A neutral atmosphere delay package for radiometric space techniques. GPS
Solut, 2008, 12: 65-70

10 Leandro R F, Santos M C, Langley R B. A North America Wide Area Neutral Atmosphere Model for GNSS applications. Navigation, 2009, 56: $57-71$

11 Yin H T. Study on the regional tropospheric delay 4-dimension modeling and applications based on the Multiple Reference Stations Networks (in Chinese). Dissertation for the Doctoral Degree. Chengdu: Southwest Jiaotong University, 2006

12 Yin H T, Huang D F, Xiong Y L, et al. New model for tropospheric delay estimation of GPS signal (in Chinese). Geom Inf Sci Wuhan Univ, 2007, 32: 454-457

13 Yang L. The theory and research of atmosphere affection to GPS surveying (in Chinese). Dissertation for the Doctoral Degree. Zhengzhou: The PLA Information Engineering University, 2001

14 Song S L, Zhu W Y, Chen Q M, et al. The establishment of the Chinese model (SHAO) for the tropospheric delay (in Chinese). In: CSNC2010, May 19-21, Beijing, China, 2010

15 Chen Q M, Song S L, Zhu W Y. The establishment of the global model (SHAO-G) for the tropospheric delay (in Chinese). In: CSNC2011, May 18-20, Shanghai, China, 2011

16 Dow J M, Neilan R E, Rizos C. The International GNSS Service in a changing landscape of Global Navigation Satellite Systems. J Geod, 2009, 83: 191-198

17 Jin S G, Park J U, Cho J H, et al. Seasonal variability of GPS-derived zenith tropospheric delay (1994-2006) and climate implications. J Geophys Res, 2007, 112: D09110

18 Kanamitsu M, Ebisuzaki W, Woollen J. NCEP-DEO AMIP-II Reanalysis (R-2). Bull Atmos Met Soc, 2002, 83: 1631-1643

19 Thayer G D. An improved equation for the radio refractive index of air. Radio Sci, 1974, 9: 803-807

20 McCarthy D D, Petit G. IERS Technical Note 32, Verlag des Bundesamts für Kartographie und Geodäsie, Frankfurt am Main, 2004

Open Access This article is distributed under the terms of the Creative Commons Attribution License which permits any use, distribution, and reproduction in any medium, provided the original author(s) and source are credited. 